\title{
Al Morrison
}

\section{Picking up the Pace in Public Services}

Introduction

\section{Following the reforms of the public management system} in the 1980s, legislative change and programmes of work to develop and shape the system have occurred at various times. The work programmes have tended to come and go, with mixed success, each designed around maintaining the strengths that accountability for outputs has brought to public sector agencies while increasing the focus on achieving outcomes.

The Better Public Services programme currently under way is the latest manifestation. In essence, it is about the system reform required to get the public services to think and operate across the whole government system and beyond to effectively address complex issues that have been holding New Zealand back from continuing prosperity, and to create opportunities through collaborative endeavour. As with past efforts, it is about retaining the strengths of individual agency accountability within a system which encompasses collective responsibility. If the stop-go history of reform since the 1980s is to be avoided, then the task for the public sector is to build continuity and momentum around the current reform and embed it into the whole-of-government system. This means a state services system that is widely recognised as supporting the government of the day, meeting agency accountabilities, and being an excellent steward of public resources for the benefit of present and future generations of New Zealanders.

This article traces aspects of the state sector management system from the 1980 s to the present day with a view to identifying the threads that weave through the various periods of activity. The objective is to bring to the surface the continuity of thought and action that is the basis for a smooth and continuous pathway to enduring reform.

\section{The spirit of reform}

In 2013 Parliament passed some significant changes to the State Sector, Public Finance and Crown Entities acts. The two major parties supported the state sector changes, and minor party objections did not run counter to the fundamental direction of change. All parties supported the public finance and Crown entities changes. The direction of change was to strengthen the accountability of state sector agencies to work better together on problems and opportunities that required collaborative effort, and to make it easier for them to do so. The cross-party support may have defined the common position without meeting the full appetite for change, but it was a good indication of the agreed broad direction of change.

The legislative changes were designed to support the government's Better Public Services programme. That programme continues a reform pathway that has been developing through successive governments since the reforms of the 1980s. The reform pathway has not been 
1984

'The decision-making processes themselves constrain the Government's ability to act in the community's collective interest.

Economic Management, briefing to the incoming government

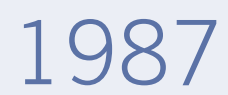

'Improved management
is treated as a whole.'

Government Management, briefing to the incoming government

1996 'The next steps in New Zealand states sector reform... will have to do for outcomes what has been accomplished for outputs.'

Allen Schick, The Spirit of Reform: managing the New Zealand state sector in a time of change

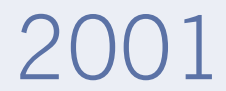

'Weaknesses include the lack of a systemic approach to setting outcome goals and priorities.'

Report of the Advisory Group on the Review of the Centre

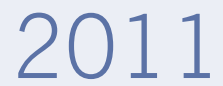

'Getting better outcomes for New Zealanders - within appropriate and constitutional settings - is the highest calling for government and the state services.'

Better Public Services Advisory Group Report

smooth, but underlying the fits and starts there is a broad direction of change that has clear and consistent objectives:

- to create a state sector that is increasingly responsive to the needs of New Zealanders in a fast-changing and technological world;

- to deliver the support and services needed for the present and future well-being of New Zealanders and prosperity of New Zealand efficiently and effectively; and

- to work together across the state sector and beyond to address difficult and complex issues and create the opportunities that arise from thinking and operating collaboratively.

It is the last objective of the three that has proved particularly elusive, and the Better Public Services Advisory Group's report of December 2011 focused on meeting that challenge in particular.

The present government and the state sector agencies have picked up the report's recommendations through a number of projects and initiatives. These include the ten result areas; functional leads; heads of profession; shared services; sector group cross-cutting initiatives; a stronger focus on leadership development; and agency and chief executive performance monitoring and management. While
The challenge we face is to retain the prevailing strengths of vertical accountability, and build on to it a greater sense of horizontal accountability. That is the system change required to tackle the thorny issues successfully and create the opportunities that arise from thinking and operating collaboratively. This is not a revelation.

Clear action points have been designed to improve the system since the reforms of the 1980s. Legislative change to support the direction of reform has been developed consistently by successive governments. That is not quite the case with work programmes and projects for change, which have been started, stalled and reinvented in new forms by successive ministers, governments and public service leaders. The different approaches have caused the implementation of system improvement to be patchy. Even so, the direction of travel has been consistent.

This has been most evident in the 2000s, with the Report of the Advisory Group on the Review of the Centre (Advisory Group on the Review of the Centre, 2002) and the Better Public Services Advisory Group Report a decade later (Better Public Services Advisory Group, 2011) in many respects a mirror image of each other. That a decade separates two clearly compatible reports recommending similar change is evidence that little happened to shift the system. The key elements of the directional change in both reports are a state sector that:

- effectively serves the government of the day, supporting it to achieve its priorities;

- meets the developing and changing needs of citizens and prioritises the things that matter most to them and makes the most difference for New Zealand; and

- efficiently and effectively executes its stewardship role within each agency and across the system.

We have reached a point where the need for the state sector agencies to exercise individual stewardship accountabilities while taking responsibility as stewards across the whole system is urgent. What it will take is momentum around a reform programme which endures beyond changes of government and state sector leaders. 
The problem of reform continuity in a democratic political system is well highlighted in a recent study carried out by the Institute for Government in the United Kingdom. The study reviews four distinct reforms between 1987 and 2012. In a foreword to the study, the director of the institute, Peter Riddell, states:

The authors make the key point about the dangers when senior officials and ministers move on, and their successors do not see the need to back a reform agenda associated with their predecessors. This applies not only to ministers of the same party but even more when there is a change of government and new ministers likely to be unfamiliar with Whitehall reforms. (Panchamia and Thomas, 2014, p.1)

The economic and management theories and principles underpinning the New Zealand reforms of the 1980s are well documented, and need no recounting for the purposes of this article. What those reforms confronted was a public service focused on what it took to run the public service, rather than what it took to efficiently and effectively benefit New Zealand and New Zealanders. While the success of those reforms is also well recognised, the main weakness to emerge is around the way agencies have developed into silos and become overly protective of their policy, information and operations. What gets lost in the fragmentation is the collective action required to deliver the common good. The incentives and accountabilities push agencies towards protecting their resources and capability from being diverted into endeavours that compromise their ability to show up well. Over time, an organisational culture is built which makes it very difficult to deal with complex issues that need collective action to resolve.

In essence, this is the failure of the almost singular focus on outputs that was entrenched through the legislation supporting the 1980s reforms. While the focus on outputs did create managerial accountability, it came at the price of too little attention being paid to the outcomes they were designed to achieve.
The focus on outputs was not an oversight. Typically, outcomes sit across a spectrum and require connected-up activity across a broad system to achieve. They were seen as the business of ministers. The combination of ministers being held accountable for their portfolio responsibilities and agencies similarly working to their siloed accountabilities meant that many issues requiring crosscutting collective action were inadequately addressed.

The impact of putting outcomes in the too-hard basket was a matter of much discussion through the 1990s; in 1995 the State Services Commission and Treasury commissioned Allen Schick, a professor of public policy at the University of Maryland, to review where the reform process was up to and recommend the way ahead. In setting the context, Schick reported:

The organisational cocoon of the old State sector has been broken open and structures reshaped through the application of the reforms' overriding principles. The State sector is more efficient, productive and responsive, and there generally has been significant improvement in the quality of services provided to New Zealanders. However, as with any leading technology, it may now be time to 'debug' elements which have not worked as well as anticipated. (Schick, 1996, executive summary)

Maintaining momentum around reform is a challenge. Inevitably the new becomes the old, shortcomings and unintended consequences emerge, and, unless refreshed, the reform agenda withers on the vine. Reframing is therefore important to the long game of transformational change. As Schick states, 'When it comes to culture, staying power is the all-important indicator. Only after a lapse of years can one ascertain whether the reforms have become the new operating culture or merely the passing fashion of public management' (ibid., p.51).

One of the issues Schick identified as requiring reframing was the issue of accountability. He complimented New Zealand on building accountability into the framework of government to an extent that no other country had accomplished, but he drew a distinction between accountability and responsibility:

The words lead down very different managerial paths. Responsibility is a personal quality that comes from one's professional ethic, a commitment to do one's best, a sense of public service. Accountability is an impersonal quality, dependent more on contractual duties and informal flows. Ideally, a manager should act responsibly, even when accountability does not come into play. As much as one might wish for an amalgam of the two worlds, the relentless pursuit of accountability can exact a price in the shrinkage of a sense of responsibility ... In the new world of New Zealand management, it is urgent to uphold the old-fashioned tenets of managerial responsibility, while strengthening the modern instruments of managerial accountability. (ibid., pp.84-5)

This is at the heart of the balance the current system reform process needs to achieve: that chief executives are accountable for the stewardship of the people, assets and resources entrusted to their agency's care, but they also have a responsibility for stewardship of the whole public services system.

This is a difficult balance that has significant leadership impacts. The chief executive must be able to judge when the agency needs to contribute to a collaborative exercise, and be prepared to reprioritise agency work to free up the resources so it can do so. In effect, they need to 'take one for the team' when the benefits from collaborative activity come at some cost to their agency activity. The system needs to acknowledge and reward that approach. Likewise, ministers need to sanction the collaborative approach and work within it. Shifting the system in that direction is a challenge to the cautious, risk-averse and compliant culture that a singular focus on output accountability encourages. That is a culture that restrains the passion and commitment of state servants to make a difference. That, in turn, constrains the innovative, experimental approaches 
required to work on the important issues that require the public services to work across the system.

During the 1990s the government's approach to the reform process was to introduce strategic result areas (SRAs). SRAs were designed to link the government's long-term objectives with the department's operational activities. The approach continued to locate accountability for outcomes with ministers, while agencies worked to key result areas (KRAs), which in effect meant outputs. The approach had little impact in terms of system change. At the ministerial level, a change in prime minister brought the creation of ministerial teams around particular projects, such as Strengthening Families, which required departments to senior management, and a programme of innovation. $^{2}$

Cabinet signed off on the State Services Commission's Managing for Outcomes programme in August 2002, effectively endorsing an approach that had been designed earlier. The approach became bogged down in the complexity of linking outputs directly to outcomes. It revealed the weakness of fragmentation, because typically the outcomes to which an agency's outputs contributed could only be achieved by multiple agencies working together, and that wider front was not organised and operating. Some crosscutting initiatives did emerge, including social sector and economic development theme teams, the justice pipeline and the natural resource sector group. The State

\section{Cabinet signed off on the State Services}

\section{Commission's Managing for Outcomes programme in August 2002, effectively endorsing an approach that had been designed earlier.}

work formally together. But that approach went out with a change in government in 1999.

The new government commissioned an advisory group to review the central agencies, which in reality meant a review of how well the public management system was responding to the needs and expectations of ministers and citizens. The advisory group's report - the Report of the Advisory Group on the Review of the Centre (2002) - focused on three core areas for change:

- achieving better integrated, citizenfocused service delivery;

- fragmentation and new ways to get agency collaboration on key crosscutting issues; and

- improving leadership and building workforce capability around a unifying sense of values.

The government responded with regional 'circuit breaker' teams focused on specific issues, ${ }^{1}$ Crown entity governance proposals, an executive leadership programme to strengthen
Services Commission designed a set of development goals around a trusted state sector that attracted and developed top talent and made it easy and effective for New Zealanders to access services and work with government. But the goals did not seem to fit into any integrated initiative to determine what that meant at the system level and implement it.

Change over this period tended to be ad hoc rather than enduring and systematic. This was in large part because the relationship between the central agencies was too weak to provide the collective leadership required, which combined with waning ministerial interest.

Ministers reignited their interest in 2006 and adopted a suggestion by the three central agencies to carry out another Review of the Centre, which in effect was a performance review of the public services system. That led to the establishment of the Performance Improvement Framework (PIF), which began as a score-sheet of performance but has evolved into distilling agencies' four-year strategic outlook and an assessment of their current capability to achieve it. (PIF is now evolving into being the lynchpin of a process to set the fouryear strategic horizon and create a plan to show how that will be accomplished within budget, and performance measures for the chief executive out of that.) While many positive aspects endured in the wake of this review, they fell well short of transformational system reform. But they did provide a platform for change.

The change of government in 2008 coincided with challenges on three fronts which shifted the context: the global financial crisis; disaster management; and heightened frustration around the continued failure of the state sector to effectively address major issues that were holding New Zealand back. The global financial crisis forced the efficiency agenda to new heights. The government cut agency budgets and demanded that they do 'more for less'. This forced agencies to work out how they could deliver their outputs with fewer resources. They received some support, with greater flexibility to plan and budget on a fouryear cycle and to move resources between outputs.

The disaster management came about as a result of the Canterbury earthquakes, the Pike River Mine disaster and the grounding of the ship Rena on the Astrolab Reef. All three not only challenged the state sector to collaborate and coordinate, but showed that at such times it was willing and able to do so. That begged the question: why is it so difficult in ordinary times?

Part of the answer to that is, it isn't necessarily. There are numerous examples of agency cooperation. Regional operational agencies, in particular, are typically no strangers to working together and with their wider communities. But it is difficult where organisations have to think and operate across the system when the benefits fall unevenly and at the expense of their priorities and resources. That brings into stark relief the tension between an agency's stewardship accountability and its responsibility to support stewardship of the government system as a whole.

The third front was the heightened level of frustration from ministers that 
public spending had risen significantly in the 2000s but with little return for it. The problems that were holding New Zealand back and required collaboration across the system were not being solved, and in some cases getting worse. The government introduced a number of changes, including social sector trials which aimed to address specific issues at the regional and community level, functional leadership initiatives, a requirement for agencies to produce fouryear strategic financial and capability plans, and formalised sector groups with designated programmes of cooperative work. It sought new ways to broaden policy advice through sector groups, the establishment of a Productivity Commission to take a broad look at pressing issues, one-off taskforces in tax and welfare reform, contracting social advice through the Families Commission, and new consultation processes through the Land and Water Forum

The three central agencies formed a Corporate Centre (later clarified to include the functional leads, and the government chief information officer in particular) to lead measure and monitor system change. Legislative change strengthened the powers of the state services commissioner, particularly around leadership for system change.

The main focus for public sector reform came with the appointment in May 2011 of the ministerial Better Public Services Advisory Group to report on ways to shift the system. Its report clarified the two key objectives for change. The first is getting better outcomes for New Zealanders. This means mobilising across the public service to tackle the complex and 'thorniest' issues (it cited a list of lingering social, environmental and economic issues). The second key objective is to improve the quality, responsiveness and value-for-money of state services.

The Better Public Services report was in many respects a mirror image of the Review of the Centre a decade earlier, and it spawned a wealth of activity which had its nucleus in ten government result areas. The urgency and pragmatism around all this activity saw the language of outcomes replaced by results. Results in this context are effectively bite-sized pieces of an outcome (similarly to what were previously called intermediate outcomes). And the government talked about wanting to see tangible progress towards its larger objectives, which in effect was a renaming of outcome indicators.

The open question is whether the sum total of activity from the Better Public Services programme is doing more than extracting compliance that can be delivered without agencies changing their operating model. A review of activity across the system which reported in February this year suggests that agencies are increasingly attuned to the problemsolving and opportunities created from collaborative endeavour, but that we are some distance yet from the system as a
Zealanders. Those social, environmental and economic outcomes have not changed greatly over time, although some issues have become worse and the urgency to address them has become greater. The only area of reform where policy has lurched is over the ownership of the state's commercial assets. That is a defining political issue which sits on the edges of public management reform. In respect to state services, there is a consistent desire to retain the strengths of agency accountability for outputs while attempting to get a better balance between that and achieving outcomes.

Given over a quarter of a century of reform effort, why have the public services been prepared to live with the glaring results of failure for so long?

\section{For the first time since the 80 s, reform had the involvement and backing of ministers and the public sector working in tandem.}

whole operating that way as a matter of course. The ambition extends well beyond that to a point where agencies continue to deliver their lead accountabilities, but think and operate innovatively across the system, taking collective responsibility for common goods. That involves transformational change of the current whole-of-government system and a significant shift in the current culture.

\section{Overview}

It is possible to see a consistent direction of reform in government management from the 1980s to the present day, particularly so with the progressive evolution of legislative change to support system change. No government has turned the clock back in any significant way in that respect.

Programmes of change are another matter. They have been periodic, slow and repetitive. Even so, underpinning the repetition of thinking and activity and rebranding that has taken place in fits and starts there is a consistent ambition to achieve the outcomes that will make the most difference to the lives of New
The roles and responsibilities of the central agencies, and the State Services Commission in particular, were significantly reduced by the decentralisation of accountabilities to individual agencies. This led to a sense of a weakened commission that has taken a long time to redefine itself. Consequently, subsequent reform after the 1980s was typically led by ministers, in bursts of activity followed by periods of inertia, each with little reference to the previous activity. Agencies responded to what was required, without embracing the spirit of ongoing reform that would have required them to redress the high degree of autonomy they enjoyed and deliver resources across the system at some cost to their own agency's priorities. In short, the state sector did not take ownership of reform and design, nor lead an integrated programme of change to improve the system.

But there is reason to be optimistic. While ministers generated the Better Public Services programme, the report that crystallised the direction of reform was led by the public sector, working with private sector advisers and engaging with 
the public sector chief executives. For the first time since the 80 s, reform had the involvement and backing of ministers and the public sector working in tandem.

The state services commissioner, Iain Rennie, has stated that 'this system wide change is the business of the commission, and the only business of the commission' (State Services Commission, 2014, p.4), and he has reorganised the way the commission and the governance of system reform operates to align with that and allow him to focus on leading that system change. This means that state services working co-operatively in the collective interests of New Zealanders is the lens for all the commission's work. 'The State Sector has the mandate from Government and the opportunity to fundamentally reshape how we work and deliver services. We are in the throes of the most significant changes the State Sector has seen for 25 years.' Achieving that level of reform is, says Rennie, 'the most significant changes the State Sector has seen for 25 years, and will result in a fundamental reshaping of how the State Sector works and delivers services' (ibid., p.2).

Public service chief executives affirmed their commitment to that reform at a meeting in March 2014 at Brackenridge retreat, Martinborough, where they crafted and signed their own Brackenridge Declaration.

\section{Conclusion}

There has been a consistent direction of travel for state sector reform across governments since the 1980s. The 2000s has seen a sharp focus on how a fragmented system makes it difficult to get traction on the big, intractable cross-cutting issues that require multiple agency collaboration. These are the issues that, if unchecked, will continue to hold back social, environmental and economic

\section{THE BRACKENRIDGE DECLARATION}

WE are the leadership team of the State Services:

Our purpose is:

Collective leadership for a better New Zealand

Towards this we will:

- Be collectively ambitious for New Zealand, by focusing on the needs of our customers

- Mobilise our people and resources to ensure those leading complex system-wide issues are successful

- See past any barriers and make what needs to happen, happen

- Champion state sector reform in our organisations

- Support each other as a team 'out together, back together', pick up the phone

- Collectively and individually support and implement the work of functional leaders

- Own and champion decisions of the State Sector Reform Leadership Group

- Prioritise our biannual State Services Leadership team meetings

progress for New Zealanders. Reforming the public services system to operate this way will not only address historic problems, but create opportunities.

The key to getting momentum around such reform is for the public service to create and own a system that is better fitted to delivering the results that governments of the day are committed to delivering. It must also identify and get traction on the long-term issues and opportunities that matter most to New Zealanders and will make the most difference to present and future generations. To endure, that has to attract broad support across the political system, so that it is not associated with a particular regime but is rather seen as the way the public services need to think and operate.

The State Services Commission is currently coordinating the preparation of a public services brief to the incoming government in an effort to build that support. It will set out reform progress to date, and identify where effort and change is needed to take the public services from good to great. It will not, and should not, surprise in that process. We have known the problems for years, and the levers for change. What we need to do is entrench the common understandings of the problem, and the commitment and effort that is now evident to tackle it. That is what is required to demonstrate value for money from the political-public service system.

\footnotetext{
1 There were three teams established, tasked with reducing the truancy rate, more rapid settlement of skilled migrants, and reducing the fragmentation of funding to community groups dealing with domestic violence.

2 The only example cited subsequently was the Department of Conservation's pest eradication programme which moved the mindset from controlling pests to eradicating them.
}

\section{References}

Advisory Group on the Review of the Centre (2002) Report of the Advisory Group on the Review of the Centre, Wellington: State Services Commission

Better Public Services Advisory Group (2011) Better Public Services Advisory Group Report, Wellington: Department of the Prime Minister and Cabinet

Panchamia, N. and P. Thomas (2014) Civil Service Reform in the Real World: patterns of success in UK civil service reform, London: Institute for Government
Schick, A. (1996) The Spirit of Reform: managing the New Zealand state sector in a time of change, Wellington: State Services Commission State Services Commission (2014) 'Better Public Services - next steps. A discussion paper for New Zealand's state sector chief executives', February 